National Institute of Dental Research/National Institutes of Health (United States Public Health Services grant No P5O-DE 07010).

1 Mamelle N, Meunier PJ, Dusan R, et al. Risk-benefit ratio of sodium fluoride teatment in primary vertebral osteoporosis. L ancet 1988;ii:361-5.

Riggs BL, Hodgson SF, Hoffman DL, Kelly PJ, Johnson KA, Taves D. Treatment of primary osteoporosis with fluoride and calcium. Clinical tolerance and fracture occurrence. FAMA 1980;243:446-9.

3 Lanza FL. Endoscopic studies of gastric and duodenal injury after the use of ibuprofen, aspirin, and other nonsteroidal anti-inflammatory agents. Am 7 (984:77:19-24.

4 Pashley DH, Allison NB, Easmann RP, McKinney RV, Horner JA, Whitford GM. The effects of fluoride on the gastric mucosa of the rat. $\mathcal{F}$ Oral Pathol 1984;13:535-45.

5 LeComte EJ. Clinical application of topical fluoride products - risks, benefits and recommendations. $\mathcal{F}$ Dent Res 1987;66:1066-71.

(Accepted I March 1989)

\section{Parents' beliefs about vaccination: the continuing propagation of false contraindications}

\author{
Nigel Klein, Kate Morgan, \\ Mark H Wansbrough-Jones
}

\section{Communicable Diseases Unit and Department of Paediatrics, St George's Hospital, London SW17 0QT \\ Nigel Klein, MRCP, senior house officer in communicable diseases \\ Kate Morgan, MRCP, registrar in paediatrics Mark H Wansbrough-Jones, FRCP, consultant physician and senior lecturer in communicable diseases}

Correspondence to: Dr N Klein, Department of Immunology and Infectious Diseases, Institute of Child Health, London WC1N 1EH.

BrMed f 1989;298:1687
Low immunisation rates in England remain a cause for concern. The introduction of the measles, mumps, and rubella vaccine has renewed optimism that the proposed target of $90 \%$ uptake of vaccination could be achieved by $1990,{ }^{1}$ but studies in the early 1980 s suggested that this target is unrealistic. They showed that parents and health care professionals had a poor understanding of the diseases concerned and commonly believed in mythical contraindications to vaccination. Our study aimed to reassess the importance of these obstacles to vaccination.

\section{Subjects, methods, and results}

The study was conducted at this hospital during six weeks from December 1986 to January 1987. Children aged between 3 months and 4 years who were admitted to the communicable diseases unit and two general paediatric wards were entered into the study. Their immunisation history was sought from one or both parents. If the child had not been fully vaccinated at the correct times the parents were asked their reasons for the failure or delay. If they had been advised against vaccination they were asked for the source of advice and the reasons given. We defined the advice given as appropriate or otherwise according to the Department of Health and Social Security's guidelines of 1984.

During the study period 184 children were admitted, of whom $173(94 \%)$ entered the study. A history of immunisation against measles was taken for the

Reasons given by parents for failure to immunise their children. Figures in parentheses are numbers of parents citing true contraindications according to Department of Health and Social Security's guidelines of 1984

\begin{tabular}{|c|c|c|c|c|}
\hline & Pertussis & Measles & Diphtheria, tetanus, and polio & Total \\
\hline \multicolumn{5}{|l|}{ Intercurrent illness: } \\
\hline Febrile & $4(1)$ & 5 & $1(1)$ & \multirow{2}{*}{$18(2)$} \\
\hline Non-febrile & 4 & 3 & 1 & \\
\hline \multicolumn{5}{|l|}{ Allergy: } \\
\hline To egg & 1 & $2(2)$ & & \multirow{2}{*}{17 (2) } \\
\hline Atopy & 7 & 5 & 2 & \\
\hline \multicolumn{5}{|l|}{ Convulsions: } \\
\hline In child & (3) & 2 & & \multirow{3}{*}{$8(5)$} \\
\hline In first degree relative & (2) & 1 & & \\
\hline In second degree relative & 4 & 1 & & \\
\hline \multicolumn{5}{|l|}{ Prematurity: } \\
\hline Handicap & (3) & 1 & \multirow{5}{*}{1} & $5(3)$ \\
\hline No handicap & 3 & & & $3(3)$ \\
\hline Natural infection & 1 & 3 & & 4 \\
\hline Previous reaction to vaccine & (2) & & & \\
\hline Immunosuppression & & (1) & & \\
\hline Apathy and objections & 8 & 18 & 13 & 39 \\
\hline Total & $32(11)$ & $41(3)$ & $18(1)$ & $91(15)$ \\
\hline
\end{tabular}

121 children over 16 months old. No differences were found in any of the study variables between the groups admitted to the communicable diseases unit and the paediatric wards. Uptake of immunisation (diphtheria, tetanus, and polio $89 \%(154 / 173)$; pertussis $64 \%$ (111/173); measles $64 \%(77 / 121)$ ) was similar to national figures ${ }^{2}$ and figures for Wandsworth Health Authority during 1982-6. Altogether 106 children were incompletely vaccinated, and 91 of these had missed vaccinations for inappropriate reasons: in more than a third (39) the reason was parental objection (13) or apathy (26), but two false contraindicationstemporary intercurrent infection and a history of atopy - accounted for a further third. Inappropriate advice was equally likely to have come from general practitioners, health visitors, and health clinics.

\section{Comment}

In the early 1980s several studies examined the reasons for the continuing failure to improve uptake of vaccination. ${ }^{3-5}$ Like those studies, ours highlighted serious deficiencies on the part of health care professionals in explaining and promoting immunisation. Most of the parents (96\%) reported that they had received advice from a health care professional before deciding about their child's vaccination, and in only $28 \%$ of cases was failure to vaccinate the child due to parental inertia. In the remainder it was due to inappropriate advice or parental conviction not refuted by health care professionals. These findings support those of Blair et al, ${ }^{5}$ who concluded that previous consultation with a health care professional did not significantly correlate with a parent's decision on vaccination.

Improving vaccination uptake is important, but we found that many parents, and apparently some doctors and health visitors, still viewed immunisation as a potential hazard that should be avoided if some excuse could be found. Our most important finding was that of all the cases in which the child had missed vaccinations, $38 \%$ could be attributed to either temporary intercurrent infection or atopy. This almost equalled the proportion accounted for by parental apathy and objection (42\%). If these two misunderstandings had been specifically targeted uptake of more than $80 \%$ might have been achieved.

Much hope is being invested in the new measles, mumps, and rubella vaccine, but the obstacles to full vaccination highlighted in our study clearly reflect deeply entrenched attitudes. A more directed and sustained effort will be needed to change these if we are to improve uptake of vaccination.

\footnotetext{
Begg NT, Noah ND. Immunisation targets in Europe and Britain. Br Med $\mathcal{f}$ 1985;291:1370.

2 Central Statistical Office. Social trends 18. London: HMSO, 1988:123.

3 Nicoll A. Contraindications to whooping cough immunisation-myths or realities. Lancet 1985;i:679-81.

4 Campbell AGM. Measles immunisation: why have we failed? Arch Dis Child 1983;58:3-5. 5 Blair S, Shave N, McKay J. Measles matters, but do parents know? Br Med $\mathcal{F}$
1985;290:623-4.
} 